\title{
Mixed oligopoly equilibria when firms' objectives are endogenous ${ }^{1}$
}

\author{
Philippe De Donder \\ Toulouse School of Economics \\ (IDEI and GREMAQ-CNRS) \\ John E. Roemer \\ Yale University \\ First version: September 2006 \\ This version: July 2008
}

\footnotetext{
${ }^{1}$ This paper has been presented at the ESF Exploratory Workshop on "Designing Partnerships between Government and the Private Sector: Cross-Disciplinary Perspectives" (Bristol, June 2006). We thank participants as well as two referees for their comments and suggestions. This paper has been revised while the first author was visiting Yale University. He wishes to thank Yale's Economics Department for its hospitality. The usual disclaimer applies.
} 


\begin{abstract}
We study a vertically differentiated market where two firms simultaneously choose the quality and price of the good they sell and where consumers may also care for the average quality of the goods supplied. Firms are composed of two factions whose objectives differ: one is maximizing profit while the other maximizes revenues. The equilibrium concept we model, called Firm Unanimity Nash Equilibrium (FUNE), corresponds to the Nash equilibrium between firms when there is efficient bargaining between the two factions inside both firms. We first show that such equilibria are inefficient, with both firms underproviding quality. We then assume that the government takes a participation in one firm, which introduces a third faction, bent on welfare maximization, in that firm. We study the characteristics of equilibria as a function of the bargaining weight of the welfare-maximizing faction. We show that equilibrium welfare increases with this bargaining weight, especially if consumers care a lot for the average quality of the goods provided.
\end{abstract}

Key words: mixed oligopoly, privatization, vertical differentiation, factions, partyunanimity Nash equilibrium.

JEL Classification: D21, D43, D62, H82. 


\section{Introduction}

In many countries, several sectors of activity are characterized by the presence of both public and private firms. Examples range from network industries (energy, transportation, telecommunications) to the service sectors (banking, insurance), and from health care provision to education. ${ }^{1}$ Since the 1980 s, there has been a global movement towards (at least partial) privatization of public firms. In this context, the question of the optimal degree of government ownership in a firm is a relevant one, particularly so in Europe where many network industries have recently been opened to more private competition. For instance, there is currently a debate in France about the optimal extent of privatization of the public utilities Gaz de France and Electricité de France. Examples abound beyond network industries as well: see the discussions over the optimal extent of public ownership of firms like Volkswagen or regional savings-and-loans banks in Germany, or of EADS and its subsidiary Airbus. The objective of this paper is to better understand the determinants of the optimal degree of government ownership in a firm, taking into account decisions both within and between firms.

The mixed oligopoly literature analyzes equilibria in industries with competition between a small number of firms whose objectives differ. Until recently, most of the literature has focused on the particular case of a private, profit-maximizing firm competing with a public, welfare-maximizing firm. Recent papers like those of Matsumura (1998) and White (2002) assume that a firm may be semi-public, in which case it maximizes a convex combination of profit and welfare. Matsumura (1998) shows that some partial privatization is always preferable to both full nationalization and full privatization. Likewise, White (2002) shows that the equilibrium welfare in the industry would be higher if the public firm maximized some convex combination of welfare and profits rather than welfare alone. White (2002) does not study how, in his words, to "manipulate the public firm's objective function", but this could be done by partially privatizing the firm. ${ }^{2}$

\footnotetext{
${ }^{1}$ Parris, Pestieau and Saynor (1987) contains a quantitative description of the importance of public firms in Western Europe.

${ }^{2}$ This analysis is reminiscent of the literature on strategic delegation by firms owners. Fershtman and Judd (1987) study the principal agent problem between profit maximizing owners and managers
} 
These results are driven by the strategic interactions between firms. We think it is important also to take into account the internal functioning of the firms. Seabright (2004) contends that "Firms in America or Western Europe are coalitions, products of the eighteenth century political theory of checks and balances that underlies the American Constitution. (p.172)". In the context of mixed oligopolies, the main focus has been on the conflict between workers and managers/owners. Willner (1999) starts from the observation that, while cost efficiency is often invoked as a reason to privatize, empirical findings do not give unanimous support to the claim that public firms are less cost efficient than private firms. He studies a mixed duopoly in which wages are determined by bargaining in a first stage before the two firms compete à la Cournot. He assumes exogenous and identical bargaining weights for the two firms (irrespective of their objectives) and compares the equilibrium allocations when both firms maximize profit and when one instead maximizes welfare. He obtains that nationalization of one firm is beneficial despite making this firm appear less cost efficient. Unfortunately, he does not say anything about partial government ownership of a firm. Jiang (2006) introduces partial privatization in a sequential model where the government decides first on the optimal degree of privatization of the public firm, then negotiates the wage rate with a union, and where finally the two firms choose their quantity levels (either simultaneously a la Cournot or sequentially). As in Matsumara (2002), the extent of government ownership determines the weight put on social welfare (as opposed to own profit) in the semi-public firm's objective. The main result of the paper is to show that the optimal privatization degree depends on the bargaining weight of the union (which is exogenously fixed).

The papers by Willner (1999) and Jiang (2006) represent important steps since they move away from the depiction of firms as unitary actors in a mixed oligopoly context. On the other hand, observe that internal bargaining does not affect the objective function of the firms, but rather the costs of the firm. Our approach goes one step further and endogenizes the firm's objective as a function of the bargaining weights of the

in a classical oligopolistic context and show that the optimal contract distorts the manager's incentives away from maximizing profits. 
different factions that make up the firm. Moreover, we endogenize the bargaining weights themselves.

We assume that firms are composed of (at least) two factions. One faction represents the interest of the owners, who want to maximize profit. The other faction is composed of managers, whose interests are not perfectly aligned with the owners. We assume that managers maximize revenue, ${ }^{3}$ and one can think of several reasons why this may be so, like ego-rents, career concerns (heading the largest firm in an industry means being highly visible), "empire building" temptations, etc. Like Willner (1999) and Jiang (2006), we do not model the principal-agent relationship between owners and managers, but rather assume that decisions within a firm are taken through some form of bargaining between profit-motivated and revenue-motivated agents. As a first step, we are agnostic as to the particular form this bargaining takes, and we only assume that bargaining is efficient (i.e., it results in an allocation on the Pareto frontier for the two factions inside the firm, given the decision taken by other firms in the industry). A Firm Unanimity Nash Equilibrium (or FUNE) is then a Nash equilibrium between firms coupled with unanimity between factions inside firms - i.e., a vector of firms' actions such that no other action would simultaneously increase both profit and revenue for any firm, given the actions taken by the other firms.

A laudable feature of this equilibrium concept is that equilibria in pure strategies typically exist even when the strategy space is multidimensional, which is usually not the case if the firms have a single goal (e.g., profit maximization). FUNE thus complexifies the conception of what happens inside a firm, in exchange for an intellectually satisfying simplicity in the nature of inter-firm competition.

We apply this novel equilibrium concept ${ }^{4}$ to the following setting. We assume that two firms offer a vertically differentiated good and that they simultaneously choose the quality and price of the good they offer. We assume that customers care about the characteristics (quality and price) of the good they buy, and that they may also care

\footnotetext{
${ }^{3}$ This assumption dates back at least to Baumol (1958).

${ }^{4}$ FUNE is an adaptation of the concept of party unanimity Nash equilibrium (PUNE), proposed by one of us in the study of political competition (Roemer $(1999,2001)$ ). There, political parties are composed of factions with different goals.
} 
about the average quality of the goods consumed.

There are two main reasons to use a vertical differentiation setting. First, it is a classical example where simultaneous Nash equilibria in pure strategies typically do not exist, so that researchers have modeled the game as sequential. Such a setting, then, illustrates the mathematical payoff to using the FUNE equilibrium concept. Second, vertical differentiation is a good depiction of many mixed oligopoly sectors: since the original contribution by Grilo (1994), this type of model has been applied, for instance, to public transportation (Cantos-Sanchez and Moner-Colonques(2006)), health care (Pita-Barros and Martinez-Giralt(2000)) and higher education (Romero and Del Rey (2004)). Finally, we have added the possibility that consumers may care about the average quality produced because it fits well two of the examples we have given at the start of the paper. In the automobile industry, people care about the average fuel mileage of cars because of pollution concerns. In the energy sector, the same pollution concerns drive some people to pay more for so-called "green energy": quality is here understood as the carbon content of the energy consumed. Consumers may also be concerned with the dangers inherent in the production process: many consumers, for example, are ready to pay more for electricity that is not nuclear in origin. In all these cases, the individual decision as to which good to buy exerts a consumption externality on other individuals. In any case, most of the results we obtain hold true when consumers do not care for quality. Introducing such a concern allows us to test the robustness of our results along this dimension.

We start by computing the FUNEs in our setting. There is a two-dimensional manifold of FUNEs, which can be characterized according to the relative bargaining weights of the revenue-maximizing factions in the two firms. We analyze the welfare properties of these equilibria and find that they fall short of optimality. This is not surprising because two assumptions of the fundamental welfare theorems are not satisfied: perfect competition and complete markets. Even in the absence of consumption externality, it is well known that oligopolies do not provide the optimal quality mix - see Crampes and Hollander (1995) for instance.

We then add more structure to the intra-firm bargaining by providing an explanation 
of how the bargaining weights will be determined at equilibrium. We assume that available managers differ in quality, and that higher-quality managers are attracted by firms generating larger revenues. The quality of the managers affects the bargaining weight of the revenue-maximizing faction, and thus the equilibrium revenues and profits obtained by both firms. We find the unique fixed point of this game, where the quality of the managers attracted in both firms is compatible with the revenues obtained at equilibrium, and where these revenues correspond to the (unique) FUNE with the bargaining weights implied by the managers' quality. We focus upon this FUNE, characterized by the relative bargaining weights between revenue and profit-maximizing factions in both firms, in the rest of the paper.

The public intervention we study consists in the government's taking a participation in one firm. Since it owns part of the firm, the government is entitled to designate a fraction of the directors on the board. We model this as the introduction of a third faction in this firm, with welfare maximization as its objective. To understand the impact of various levels of government intervention, we keep the relative bargaining weights between profit- and revenue-maximizing factions constant in both firms and assume that the bargaining weight of the welfare-maximizing faction increases with (or is a proxy for) the extent of government's participation. ${ }^{5}$ A single FUNE corresponds to each vector of bargaining weights, and we study the normative properties of these equilibria as a function of the extent of the government's intervention in the firm. Finally, we study how these normative properties are modified when the intensity of the consumption externality is varied, and when the identity of the firm in which the government invests is modified.

Our main results are as follows. First, in the absence of government intervention, the quality levels provided by both firms are too low, even when there is no consumption externality. Moreover, too many people consume the high quality good. The efficiency of the FUNEs (measured as the total welfare generated by any FUNE allocation compared

\footnotetext{
${ }^{5}$ As pointed out by a referee, a firm may represent a coalition between conflicting interests even under full state-ownership, with profits, total revenues or welfare as objectives. Since our analysis in terms of the bargaining weights of the factions constituting a firm, our paper is relevant even in the absence of a positive relationship between state ownership and bargaining weight of welfare-maximizers.
} 
to the maximum welfare attainable) varies from roughly $50 \%$ to $70 \%$. Second, total welfare increases monotonically with the welfare maximizer's bargaining weight, but the marginal gain in welfare tends towards zero as the bargaining weight becomes large. Third, government's intervention is especially attractive when consumers care a lot for the average quality of the good provided, as both the marginal and absolute efficiency gains from government's intervention are larger. We obtain the same qualitative features whether the government invests in the high-quality or the low-quality firm.

\section{The model}

There is a continuum of consumers, indexed by $\lambda$, distributed according to the distribution function $F$ on $[0, m]$, with density denoted by $f$. We denote by $\bar{\lambda}$ the average value of $\lambda$ and by $\lambda^{\text {med }}$ its median value. Each consumer buys one unit of a good of quality $q$, and has a utility function

$$
V(q, p, \bar{q} ; \lambda)=\lambda q+\gamma \lambda \bar{q}-p
$$

where $\bar{q}$ is the average quality consumed and $p$ the price. The second term denotes the environmental externality: each individual's utility increases with the average quality of the goods consumed (for instance, the average pollution or fuel mileage of cars). We assume for simplicity that all individuals share the same $\gamma \in[0,1]$ - i.e., that they have the same relative valuation for average quality (although absolute variation $\gamma \lambda$ varies across individuals).

There are two firms (indexed by subscript $i=1,2$ ), each providing one good. They share the same cost function, which is linear in quantity and convex in quality: ${ }^{6} c(q)$ denotes the per unit (of quantity) cost of providing a good of quality $q$. We assume without loss of generality that $q_{1}>q_{2}$ and we call firm 1 the high quality firm.

When choosing from which firm to buy, individuals do not consider their (infinitesimal) impact on the average quality of the good consumed. Individual $\lambda$ then buys from firm 1 if

$$
\lambda q_{1}-p_{1}>\lambda q_{2}-p_{2}
$$

\footnotetext{
${ }^{6}$ This is the formulaton used, among others, by Crampes and Hollander (1995).
} 
i.e., if

$$
\lambda>\frac{p_{1}-p_{2}}{q_{1}-q_{2}}=\lambda^{*}\left(p_{1}, q_{1}, p_{2}, q_{2}\right) .
$$

We then obtain that ${ }^{7}$

$$
\bar{q}=\int_{0}^{\lambda^{*}} q_{2} f(\lambda) d \lambda+\int_{\lambda^{*}}^{m} q_{1} f(\lambda) d \lambda .
$$

In each firm, two factions coexist, one maximizing profit while the other maximizes revenue. Profit in firm $i=1,2$ is given by

$$
\begin{aligned}
& \Pi_{1}\left(p_{1}, q_{1}, p_{2}, q_{2}\right)=\left[p_{1}-c\left(q_{1}\right)\right]\left(1-F\left(\lambda^{*}\right)\right), \\
& \Pi_{2}\left(p_{1}, q_{1}, p_{2}, q_{2}\right)=\left[p_{2}-c\left(q_{2}\right)\right] F\left(\lambda^{*}\right),
\end{aligned}
$$

while revenue is given by

$$
\begin{aligned}
& R_{1}\left(p_{1}, q_{1}, p_{2}, q_{2}\right)=p_{1}\left(1-F\left(\lambda^{*}\right)\right), \\
& R_{2}\left(p_{1}, q_{1}, p_{2}, q_{2}\right)=p_{2} F\left(\lambda^{*}\right) .
\end{aligned}
$$

Observe that the externality intensity $\gamma$ impacts neither profit nor revenue, since it does not impact individual demand.

We now introduce our equilibrium concept.

Definition 1 A Firm Unanimity Nash Equilibrium (FUNE) is a vector $\left(p_{1}, q_{1}, p_{2}, q_{2}\right)$ such that

(i) $\nexists\left(p_{1}^{\prime}, q_{1}^{\prime}\right)$ such that $\Pi_{1}\left(p_{1}^{\prime}, q_{1}^{\prime}, p_{2}, q_{2}\right) \geq \Pi_{1}\left(p_{1}, q_{1}, p_{2}, q_{2}\right)$ and $R_{1}\left(p_{1}^{\prime}, q_{1}^{\prime}, p_{2}, q_{2}\right) \geq R_{1}\left(p_{1}, q_{1}, p_{2}, q_{2}\right)$ with at least one strict inequality, and (ii) $\nexists\left(p_{2}^{\prime}, q_{2}^{\prime}\right)$ such that $\Pi_{2}\left(p_{1}, q_{1}, p_{2}^{\prime}, q_{2}^{\prime}\right) \geq \Pi_{2}\left(p_{1}, q_{1}, p_{2}, q_{2}\right)$ and $R_{2}\left(p_{1}, q_{1}, p_{2}^{\prime}, q_{2}^{\prime}\right) \geq R_{2}\left(p_{1}, q_{1}, p_{2}, q_{2}\right)$ with at least one strict inequality.

In words, no firm can find another pair of price and quality that would strictly increase one of its factions' objectives (revenue or profit) without decreasing its other faction's objective.

It will prove easier in the paper to use a slightly different definition of FUNEs. We introduce the following assumption.

\footnotetext{
${ }^{7}$ The upperbound $m$ is assumed to be large enough so that some people buy the high quality good.
} 
Assumption $1 \log \left(\Pi_{1}\left(p, q, p_{2}, q_{2}\right)\right), \log \left(R_{1}\left(p, q, p_{2}, q_{2}\right)\right), \log \left(\Pi_{2}\left(p_{1}, q_{1}, p, q\right)\right)$ and $\log \left(R_{2}\left(p_{1}, q_{1}, p, q\right)\right)$ are concave in $(p, q)$.

Roemer (2001, Theorem 8.2.) proves that, if Assumption 1 holds, then any FUNE is also a weighted Nash bargaining solution. We assume from now on that Assumption 1 holds and we make use of the following definition:

Definition 2 A FUNE is a vector $\left(p_{1}, q_{1}, p_{2}, q_{2}\right)$ and a pair $\left(a_{1}, a_{2}\right) \in[0,1]^{2}$ such that (i) given $\left(p_{1}, q_{1}\right),\left(p_{2}, q_{2}\right)=\arg \max \left(\Pi_{2}\left(p_{1}, q_{1}, p_{2}, q_{2}\right)-\bar{\Pi}_{2}\right)^{a_{2}}\left(R_{2}\left(p_{1}, q_{1}, p_{2}, q_{2}\right)-\bar{R}_{2}\right)^{1-a_{2}}$, and

(ii) given $\left(p_{2}, q_{2}\right),\left(p_{1}, q_{1}\right)=\arg \max \left(\Pi_{1}\left(p_{1}, q_{1}, p_{2}, q_{2}\right)-\bar{\Pi}_{1}\right)^{a_{1}}\left(R_{1}\left(p_{1}, q_{1}, p_{2}, q_{2}\right)-\bar{R}_{1}\right)^{1-a_{1}}$, where $\bar{\Pi}_{i}$ and $\bar{R}_{i}$ represent, respectively, the impasse utility of the profit-maximizing and of the revenue-maximizing factions in case no agreement is found between factions inside firm $i, i=1,2$.

We assume that, in the absence of agreement between factions inside firm $i$, this firm does not produce, so that the impasse utilities (profit or revenue) of its factions are zero: $\bar{\Pi}_{i}=0, \bar{R}_{i}=0$. The first order conditions for firm 1 at a FUNE are ${ }^{8}$

$$
\frac{a_{1}}{\Pi_{1}} \nabla_{1} \Pi_{1}+\frac{1-a_{1}}{R_{1}} \nabla_{1} R_{1}=0
$$

where

$$
\nabla_{1} \Pi_{1}=\left(\frac{\partial \Pi_{1}}{\partial p_{1}}, \frac{\partial \Pi_{1}}{\partial q_{1}}\right) \text { and } \nabla_{1} R_{1}=\left(\frac{\partial R_{1}}{\partial p_{1}}, \frac{\partial R_{1}}{\partial q_{1}}\right) .
$$

These first order conditions can be expanded to obtain

$$
\begin{aligned}
\frac{1-a_{1}}{a_{1}} & =\frac{R_{1}}{\Pi_{1}} \frac{1-F\left(\lambda^{*}\right)-\left[p_{1}-c\left(q_{1}\right)\right] f\left(\lambda^{*}\right) \frac{\partial \lambda^{*}}{\partial p_{1}}}{F\left(\lambda^{*}\right)-1+p_{1} f\left(\lambda^{*}\right) \frac{\partial \lambda^{*}}{\partial p_{1}}} \\
\frac{1-a_{1}}{a_{1}} & =\frac{R_{1}}{\Pi_{1}} \frac{-c^{\prime}\left(q_{1}\right)\left(1-F\left(\lambda^{*}\right)\right)-\left[p_{1}-c\left(q_{1}\right)\right] f\left(\lambda^{*}\right) \frac{\partial \lambda^{*}}{\partial q_{1}}}{p_{1} f\left(\lambda^{*}\right) \frac{\partial \lambda^{*}}{\partial q_{1}}}
\end{aligned}
$$

with

$$
\begin{aligned}
& \frac{\partial \lambda^{*}}{\partial p_{1}}=\frac{1}{q_{1}-q_{2}}>0 \\
& \frac{\partial \lambda^{*}}{\partial q_{1}}=-\frac{p_{1}-p_{2}}{\left(q_{1}-q_{2}\right)^{2}}<0 .
\end{aligned}
$$

\footnotetext{
${ }^{8}$ In order to save on notation, we do not report the arguments for the profit and revenue functions from now on.
} 
The first order conditions for firm 2 are obtained similarly. Observe that the externality intensity $\gamma$ does not affect the first order conditions at a FUNE.

We now look at the Pareto efficient allocations in order to compare them with FUNE allocations. Pareto allocations are defined by the triple $\left(q_{1}, q_{2}, \tilde{\lambda}\right)$. It is easy to see that the high quality good is supplied to all $\lambda>\tilde{\lambda}$ and the low quality good to all $\lambda<\tilde{\lambda}$. This is done with a simple "switching" argument: if $\lambda_{1}>\lambda_{2}$ but $\lambda_{1}$ consumes the low quality good while $\lambda_{2}$ consumes the high quality good, then a trade with side payment can be arranged making both better off.

The usual argument from quasi-linearity shows that Pareto efficiency requires maximization of the sum of consumer surplus and firms' profits

$$
W=\int_{0}^{\tilde{\lambda}} q_{2} \lambda d F(\lambda)+\int_{\tilde{\lambda}}^{m} q_{1} \lambda d F(\lambda)+\gamma \bar{\lambda} \bar{q}-c\left(q_{1}\right)(1-F(\tilde{\lambda}))-c\left(q_{2}\right) F(\tilde{\lambda})
$$

where $\bar{q}=q_{2} F(\tilde{\lambda})+q_{1}(1-F(\tilde{\lambda}))$. A Pareto optimal allocation $\left(q_{1}, q_{2}, \tilde{\lambda}\right)$ that maximizes $W$ solves the following first order conditions:

$$
\begin{aligned}
\frac{\partial W}{\partial \tilde{\lambda}} & =f(\tilde{\lambda})\left[(\tilde{\lambda}+\gamma \bar{\lambda})\left(q_{2}-q_{1}\right)-\left(c\left(q_{2}\right)-c\left(q_{1}\right)\right)\right]=0 \\
\frac{\partial W}{\partial q_{1}} & =\int_{\tilde{\lambda}}^{m} \lambda d F(\lambda)+\gamma \bar{\lambda}(1-F(\tilde{\lambda}))-(1-F(\tilde{\lambda})) c^{\prime}\left(q_{1}\right)=0 \\
\frac{\partial W}{\partial q_{2}} & =\int_{0}^{\tilde{\lambda}} \lambda d F(\lambda)+\gamma \bar{\lambda} F(\tilde{\lambda})-F(\tilde{\lambda}) c^{\prime}\left(q_{2}\right)=0 .
\end{aligned}
$$

We start by examining separately the optimality formulas for the allocation of consumers across goods and for qualities. Equation (8) gives

$$
\tilde{\lambda}=\frac{c\left(q_{1}\right)-c\left(q_{2}\right)}{q_{1}-q_{2}}-\gamma \bar{\lambda}
$$

This result is very intuitive: for given quality levels, a large concern for pollution (larger $\gamma$ ) induces provision of the high quality good to more people. Comparing with the individual decision rule (2), we immediately see that marginal cost pricing will not drive the optimal allocation of goods across customers (for given quality levels), but 
that too many consumers will buy the low quality good because they do not take into account the externality associated with their choice.

We will see in a short while how this result is modified when quality levels are set at their optimal level at the same time as the value of $\lambda$. As for qualities, putting together (9) and (10), we obtain

$$
\bar{\lambda}(1+\gamma)=F(\tilde{\lambda}) c^{\prime}\left(q_{2}\right)+(1-F(\tilde{\lambda})) c^{\prime}\left(q_{1}\right)
$$

namely that optimal qualities equalize average preferences for quality (including the pollution aspect) and average marginal cost of quality.

We now look at the simultaneous determination of $\lambda$ and of qualities. From now on, we assume a quadratic cost of quality (which corresponds to the formulation used for the simulations studied later on in the paper): $c(q)=\delta q^{2} / 2$.

Using (12) together with (11) gives

$$
\tilde{\lambda}=\bar{\lambda}+\delta\left(\frac{q_{2}+q_{1}}{2}-\bar{q}\right) .
$$

We then obtain that $\tilde{\lambda}=\bar{\lambda}$ if and only if $\bar{\lambda}=\lambda^{\text {med }}$. Moreover, with a positively skewed distribution, we have either $\tilde{\lambda}>\bar{\lambda}$ or $\tilde{\lambda}<\lambda^{\text {med }}-$ i.e., the only configuration excluded is $\lambda^{\text {med }}<\tilde{\lambda}<\bar{\lambda}$.

Finally, observe from (9) and (10) that

$$
q_{2}+q_{1}=\frac{1}{\delta}\left[2 \gamma \bar{\lambda}+\frac{\int_{\tilde{\lambda}}^{m} \lambda d F(\lambda)}{1-F(\tilde{\lambda})}+\frac{\int_{0}^{\tilde{\lambda}} \lambda d F(\lambda)}{F(\tilde{\lambda})}\right]
$$

so that by (11)

$$
\tilde{\lambda}=\frac{1}{2}\left[\frac{\int_{\tilde{\lambda}}^{m} \lambda d F(\lambda)}{1-F(\tilde{\lambda})}+\frac{\int_{0}^{\tilde{\lambda}} \lambda d F(\lambda)}{F(\tilde{\lambda})}\right]
$$

which does not depend either on $\delta$ nor on $\gamma$ ! In words, the Pareto efficient allocation of consumers across goods does not depend on the intensity of the externality when qualities are set at their optimal level. Moreover, we also have that the optimal difference 
between quality levels, $q_{1}-q_{2}$, is independent of $\gamma$ (since both $q_{1}$ and $q_{2}$ increase by the same amount with $\gamma$ ) but decreases with $\delta$.

We now turn to the allocation of goods across customers in FUNEs.

Proposition 1 Let $c(q)=\delta q^{r}$ and $r \geq 1$. Let $\hat{\lambda}$ be the solution of the equation

$$
\frac{r-1}{r} \hat{\lambda}=\frac{1-2 F(\hat{\lambda})}{f(\hat{\lambda})} .
$$

Then, in all FUNEs, $\lambda^{*}\left(p_{1}, q_{1}, p_{2}, q_{2}\right)=\hat{\lambda}$.

\section{Proof: See Appendix}

A few comments are in order. First, the proportion of people buying the low quality good is smaller than one half in all FUNEs where $r>1 .^{9}$ Second, this proportion is decreasing in $r$ as long as the density $f(\lambda)$ does not decrease too fast with $\lambda$. A sufficient condition for $\hat{\lambda}$ to be decreasing in $r$ is that the hazard rate function $f(\lambda) /(1-F(\lambda))$ is non decreasing in $\lambda$. This assumption is satisfied for a large number of distributions, starting with the uniform one (for which the fraction of the population who purchase the low quality good at any FUNE approaches one-third of the population in the limit as $r$ becomes large). The intuition for this result is that, as the cost of providing quality becomes more convex, the quality gap between the two goods decreases and more people buy the high quality good (provided that the density of people does not decrease too fast as the valuation for quality increases). Finally, comparing equation (13) and Proposition 1 , we see that the goods' allocation in FUNEs is generically not optimal when $r=2$.

We now turn to numerical simulations in order to shed more light on the FUNE allocations and on their normative properties.

\footnotetext{
${ }^{9}$ If $r=1$, then exactly one-half of the population purchases the high (low) quality good at any FUNE.
} 


\section{$3 \quad$ FUNEs without government intervention}

We study numerically ${ }^{10}$ FUNEs with a lognormal distribution of $\lambda$ such that $\bar{\lambda}=40$ and $\lambda^{\text {med }}=30$ while $c(q)=q^{2} / 3$. We obtain a bidimensional manifold of FUNEs. This manifold is depicted in the (price, quality) space on Figure 1. Figure 1 depicts 3800 FUNEs which have been sorted by increasing order of the high quality price. Each FUNE vector $\left(p_{1}, q_{1}, p_{2}, q_{2}\right)$ is plotted with the same color, that goes smoothly from blue for the lowest values of $p_{1}$ to red for its highest values. The ordered pairs $\left(p_{i}, q_{i}\right)$ on the diagonal of the price-quality plane are associated with the high quality firm 1 , and the ones on the semi-circle are associated with the low quality firm 2 . There are FUNEs where the two firms play strategies that are close to one another (the blue FUNEs) and ones where they play strategies that are very different (the red end of the spectrum).

[Insert Figure 1 around here]

Obviously, the low quality firm charges a lower price than the high quality firm (if it were not the case, it would not have any demand for its product). For all FUNEs, we have that, in both firms, the profit-maximizing faction wishes to increase price and decrease quality, while the revenue-maximizing faction wishes to do exactly the opposite. Indeed, as can be shown from the first order conditions (3), in each firm the profitmaximizing faction would like to go in the exact opposite direction (in the (quality, price) space) to the one favored by the revenue-maximizing faction (i.e, gradients point into opposite directions). Also, we always observe, in all FUNEs, that the gradient of the profit-maximizers is steeper in the $(p, q)$ plane for firm 1 than for firm 2 -i.e., although the general direction towards profit-maximization is the same for both firms (gradient pointing towards the south-east for all points in Figure 1), the mix of decrease in quality and increase in price is not the same, with smaller cuts in quality (relative to increases in price) in the low quality firm 2 than in the other firm.

The main regularities obtained (in all FUNEs) are as follows:

\footnotetext{
${ }^{10}$ Finding FUNEs requires solving 4 equations (first order conditions (5) and (6) for firm 1, and similar equations for firm 2) in 6 unknowns $\left(p_{1}, q_{1}, p_{2}, q_{2}, a_{1}\right.$ and $\left.a_{2}\right)$. We randomly draw a very large number of pairs $\left(a_{1}, a_{2}\right)$ and attempt to solve for the other 4 unknowns. We also check that the second order conditions are satisfied.
} 
- Profit is lower in firm 1 (the firm producing the high quality good) than in firm 2.

- Revenue is larger in firm 1 than in firm 2.

- The relative bargaining power of the revenue-maximizers, $\alpha_{i}=\left(1-a_{i}\right) / a_{i}$, is higher in firm 1 than in firm 2: $\alpha_{1}>\alpha_{2}$. Moreover, in all FUNEs, $\alpha_{1}>1$ - i.e., the revenue-maximizers have more bargaining power than the profit-maximizers in firm 1 in all FUNEs.

The next Result summarizes the descriptive characteristics of the FUNEs:

Result 1 In all FUNEs, profit is lower and revenue is larger in the high quality firm, while the relative bargaining weight of the revenue maximizers is larger in that firm than in the low quality firm.

We now turn to the normative properties of the FUNEs. We obtain the following regularities:

- The qualities offered by both firms at equilibrium are lower than the optimal qualities, whatever the value of $\gamma$. The high quality good is especially deficient (its value varies from 38 to 66 in FUNEs while its optimal values goes from 160 for $\gamma=0$ to 220 for $\gamma=1$; the low quality level varies from 35.7 to 42.5 in FUNEs while its optimal value goes from 43.6 for $\gamma=0$ to 103.6 for $\gamma=1$ ).

- Proposition 1 has shown that the equilibrium market share (in volume) $F\left(\lambda^{*}\right)$ is the same in all FUNEs and is not affected by the value of $\gamma$. We also know that the optimal market share is not affected by $\gamma$ either. Comparing both, we obtain that too many people consume the high quality good in all FUNEs, compared to the global optimum: $62.5 \%$ vs $14.2 \%$.

- The average quality of goods sold in all FUNEs is lower than the optimal average quality, whatever the intensity of the externality: the first effect mentioned above (both qualities are too low) is larger than the second one (too many people buying the high quality good). 
We summarize the normative properties of the FUNEs in the following Result:

Result 2 In all FUNEs, and whatever the value of the externality intensity $\gamma$, the qualities offered by both firms as well as the average quality provided are lower than optimal, while too many people consume the high quality good.

We already mentioned in section 2 that modifying the value of $\gamma$ does not impact the FUNEs, since $\gamma$ does not appear in the first order conditions (5) and (6). The value of $\gamma$ does not affect the optimal share of people consuming either good, as shown in (13). On the other hand, raising $\gamma$ increases the value of the optimal qualities of both firms, as is intuitive and can be shown from equations (9) and (10). As $\gamma$ increases from 0 to 1, we then have that, for any given FUNE, the same people buy from the same firm but that the quality of the good they buy becomes more and more sub-optimal. In terms of welfare, observe from (1) that total consumer surplus increases mechanically with $\gamma$ (for any given FUNE) while profit (the other component of welfare) is not affected by $\gamma$. At the same time, the maximum aggregate welfare (corresponding to the Pareto optimal allocation) also increases with $\gamma$. We are interested in the efficiency of FUNEs, obtained by dividing total welfare at equilibrium by the maximum welfare attainable. With both the denominator and the numerator increasing with $\gamma$, the comparative statics of this efficiency measure is a priori ambiguous. Table 1 summarizes the numerical results we obtain.

Table 1: Efficiency of FUNEs as a function of $\gamma$.

\begin{tabular}{|l|l|l|l|}
\hline Efficiency: & minimum & maximum & average \\
\hline$\gamma=1$ & $47.9 \%$ & $70.8 \%$ & $55.8 \%$ \\
\hline$\gamma=0.5$ & $55.5 \%$ & $76.7 \%$ & $63.3 \%$ \\
\hline$\gamma=0.25$ & $58.7 \%$ & $76 \%$ & $65.8 \%$ \\
\hline$\gamma=0$ & $59.6 \%$ & $68.8 \%$ & $64.8 \%$ \\
\hline
\end{tabular}

The second column in Table 1 gives the minimum efficiency attained over the set of FUNEs, the third column the maximum efficiency and the last column the average efficiency across FUNEs, assuming that they are all equiprobable. We obtain that FUNEs are far from optimal even in absence of externalities $(\gamma=0)$. While the minimum efficiency is monotonically decreasing with the intensity of the externality, it is not the 
case for the maximum as well as the average efficiency. Clearly, the average efficiency depends on the assumption that all FUNEs are equiprobable, which is a very crude one. For instance, Roemer et al. (2005), which uses a solution concept similar to FUNEs but applied to political competition, computes a kernel density function of the bargaining powers (which are the unknown parameters in our problem) to control for the fact that some regions of bargaining-power-space may occur much more frequently than others.

We have checked the robustness of these regularities to two types of variations: changes in the distribution function $f(\lambda)$ and in the cost function $c(q)$. As for the distribution function, we have performed simulations with lognormal distributions with, on one hand, larger values of the average $\lambda$ but the same median $\lambda$ (which corresponds to increasing the positive skewness of the distribution) and with, on the other hand, the same $\bar{\lambda}$ but a larger value of $\lambda^{\text {med }}$ (which corresponds to more symmetrical distributions, while keeping $\lambda^{\text {med }} \leq \bar{\lambda}$ ). As for the cost function, we have kept the functional form $c(q)=\delta q^{r} / 2$ and we have assessed the impact of varying the value of $\delta$ while keeping $r=2$, as well as the impact of varying $r$ while keeping $\delta=2 / 3$. In all cases we have studied, the set of FUNEs has the same appearance as in Figure 1 (although the precise location of equilibrium points of course changes) and the regularities reported in Results 1 and 2 hold true in all cases. Also, the efficiency of all FUNEs remains quite low as in Table 1. For instance, the highest efficiency we obtain across all FUNEs and all simulations corresponds to $77.8 \%$ with $\gamma=1$ and a lower value of $\delta$ than the one studied extensively above.

We are thus reasonably confident that the regularities reported above are robust to variations in both the cost function and the distribution function. The next step in our analysis consists in selecting one FUNE by endogeneizing the factions' bargaining weights inside both firms.

\section{Endogenous bargaining weights}

Up to now, we have not provided any explanation as to why intra-firms bargaining powers are what they are at equilibrium. In other words, any pair of bargaining powers consistent with Definition 2 constitutes, together with the associated vector of prices 
and qualities, a FUNE. This is the reason why we obtain a two-dimensional manifold of FUNEs. In this section, we open the bargaining powers' "black box" and provide an explanation as to how their value is determined. Providing such an explanation has an obvious interest by itself. Moreover, it will allow us to narrow down the set of equilibria and indeed to obtain unicity.

We assume that there is a pool of available managers, and that these managers differ in some attribute that we call for the moment "quality". The average quality of this pool is denoted by $\mu$. One half of the managers ends up working in each of the two firms, so if we denote the average quality level of the managers in firm $i$ by $\mu_{i}$, we obtain that

$$
\frac{\mu_{1}}{2}+\frac{\mu_{2}}{2}=\mu
$$

Managers are attracted by firms generating a higher revenue level, for the reasons indicated in the introduction (ego rents, etc.). Since managers have to choose between two firms, the average quality of the managers attracted in firm $i$ will be an increasing function of the revenue share (or market share in value) $r_{i}=R_{i} /\left(R_{1}+R_{2}\right)$ of this firm. This relationship, which is like a supply function for managerial quality, is summarized by the following increasing function

$$
Q\left(r_{i}\right)=\mu_{i}, \quad i=1,2,
$$

with $Q\left(r_{1}\right)+Q\left(r_{2}\right)=2 \mu$. It should be plain that $Q(0.5)=\mu$ and that the steeper the slope of $Q$, the more mobile the managers.

We need to define what difference the managers' quality makes in each firm. We assume that managers' quality affects the relative bargaining weights of the two factions in each firm. Now, we have that, in all FUNEs, revenue is higher in the firm where the relative bargaining power of the revenue-maximizers is larger than in the other firm. We make the assumption that the relative bargaining weight of the revenuemaximizing faction is increasing in the average quality of the managers in that firm. In that sense, one could talk of manager's cleverness or efficiency, rather than quality, with cleverer/more efficient managers better able to play the boardroom games in order to reinforce their bargaining power as revenue maximizers. Formally, we assume that 
the relative bargaining weight of the revenue-maximizers is increasing in the managers' quality and represented by the function $a\left(\mu_{i}\right)$.

A FUNE with endogenous bargaining weights (eFUNE) is then a FUNE with the additional requirements that (i) the relative bargaining weight of the revenue-maximizers in each firm is obtained from the average quality of the managers in this firm and (ii) the average quality of the managers in each firm is a function of the equilibrium revenue shares of the firms. Formally,

Definition 3 A FUNE with endogenous bargaining weight (eFUNE) is a vector $\left(p_{1}, q_{1}, p_{2}, q_{2}\right)$, a pair $\left(a_{1}, a_{2}\right) \in[0,1]^{2}$ and an assignment of managers of quality $\mu_{i}$ to firm $i$ such that (i) given $\left(p_{1}, q_{1}\right),\left(p_{2}, q_{2}\right)=\arg \max \left(\Pi_{2}-\bar{\Pi}_{2}\right)^{a_{2}}\left(R_{2}-\bar{R}_{2}\right)^{1-a_{2}}$, (ii) given $\left(p_{2}, q_{2}\right),\left(p_{1}, q_{1}\right)=\arg \max \left(\Pi_{1}-\bar{\Pi}_{1}\right)^{a_{1}}\left(R_{1}-\bar{R}_{1}\right)^{1-a_{1}}$, (iii) $Q\left(\frac{R_{i}}{R_{1}+R_{2}}\right)=\mu_{i}, \quad i=1,2$, (iv) $a_{i}=a\left(\mu_{i}\right), \quad i=1,2$.

Generally, there will be locally unique such equilibria, if they exist at all. The unicity argument can be seen from looking at the following mapping: starting from an allocation of managers $\left(\mu_{1}, \mu_{2}\right)$, the function $a\left(\mu_{i}\right)$ gives the relative bargaining weight in each firm, from which we obtain the corresponding FUNE (which satisfies equations (i) and (ii) in the above definition). We then obtain the revenue share of both firms, which in turn allows us to compute the equilibrium average qualities of managers in both firms via the equation $Q\left(r_{i}\right)$. We are looking for a fixed point of this mapping. The existence problem comes from the fact that there may exist pairs $\left(\mu_{1}, \mu_{2}\right)$ for which no FUNE exists.

We use the following functional forms in our simulations: $\mu=1, Q\left(r_{i}\right)=2 r_{i}$ and $a\left(\mu_{i}\right)=1 /\left(1+5 \mu_{i}^{3}\right)$, so that the relative bargaining weight of the revenue-maximizers in firm $i$ is given by $\alpha\left(\mu_{i}\right)=5 \mu_{i}^{3}$. We obtain a unique eFUNE, with $p_{1}=804, q_{1}=48.4$, $p_{2}=617, q_{2}=40.5, \Pi_{1}=14.5, R_{1}=503, \Pi_{2}=26.8, R_{2}=231.5, r_{1}=68.5 \%, \alpha_{1}=12.85$ and $\alpha_{2}=1.25$. Note that the equilibrium eFUNE qualities are close to the average qualities obtained in all FUNEs assuming that they are all equi-probable (which are 46 for firm 1 and 42.5 for firm 2). 
We keep this particular eFUNE, which we denote by eFUNE $E_{0}$, as the starting point for the rest of the paper. As we want to test the robustness of the results obtained in the following sections, we also consider two variations. In the first variation, we keep the function linking $\mu$ to $\alpha$ unchanged $\left(\alpha\left(\mu_{i}\right)=5 \mu_{i}^{3}\right)$ but we increase the mobility of managers across firms by making the function $Q(r)$ steeper around $r=1 / 2$. Intuitively, increasing the sensitivity of managers to the revenue share should make firm 1 more attractive to them (since $r_{1}>1 / 2$ ), resulting in an increase in $r_{1}$ at equilibrium. This is what we obtain in the unique eFUNE (which we denote by $\mathrm{eFUNE}_{\mathrm{var} 1}$ ) arising from the new formulation ${ }^{11}$, with $r_{1}$ increasing from $68.5 \%$ (in $\mathrm{eFUNE}_{0}$ ) to $69.9 \%$. The other variables associated to eFUNE $\mathrm{var}_{1}$ are $p_{1}=971, q_{1}=53, p_{2}=694, q_{2}=41.3, \Pi_{1}=20.8$, $R_{1}=607, \Pi_{2}=47.2, R_{2}=260.3, \alpha_{1}=14.6$ and $\alpha_{2}=0.93$.

In the second variation we consider, we keep the $Q($.$) function as above (Q(r)=2 r)$ but we decrease the convexity of the relationship between relative bargaining weight of managers and their quality by using $\alpha\left(\mu_{i}\right)=5 \mu_{i}^{2}$. Intuitively, such a modification should decrease $r_{1}$, since it decreases the relative bargaining power of revenue-maximizers in firm 1 (where $\mu_{1}>\mu=1$ since $r_{1}>1 / 2$ ). This is what we obtain in the unique eFUNE (which we denote by eFUNE $\mathrm{var}_{\mathrm{v} 2}$ ) based on the new formulation, with $r_{1}$ decreasing from $68.5 \%$ (in $\mathrm{eFUNE}_{0}$ ) to $65.1 \%$. The other characteristics of $\mathrm{eFUNE}_{\mathrm{var} 1}$ are that $p_{1}=547$, $q_{1}=40.2, p_{2}=488, q_{2}=37.7, \Pi_{1}=5.25, R_{1}=342, \Pi_{2}=5.4, R_{2}=183.1, r_{1}=65.1 \%, \alpha_{1}=8.9$ and $\alpha_{2}=2.26$.

\section{Government intervention in the high quality firm}

From now on, we study the impact of public intervention into this industry. Public intervention is justified by the unappealing normative properties of FUNEs (see section 3 and especially Table 1), and could take several forms. We focus on one public intervention, namely the government's taking a participation in the high-quality firm. ${ }^{12}$ Taking

\footnotetext{
${ }^{11}$ We use $Q(r)=2^{\sigma} r^{\sigma}$ if $r \leq 1 / 2$ and $Q(r)=2-2^{\sigma}(1-r)^{\sigma}$ if $r>1 / 2$, with $\sigma=1.1$.

${ }^{12}$ We assume that there is no government expenditures associated to taking a participation in the firm. We could easily introduce such expenditures by assuming that the government buys shares on the market. The price of these shares would then be related to the profit level attained by that firm before government intervention - i.e., at the eFUNE obtained in the previous section. Note that such expenditures (which constitute a transfer between government and the firm's private owners) would not
} 
a participation in a firm allows the government to appoint a fraction of the managers (or directors) of that firm. In our setting, this means that government intervention introduces a third faction into firm 1 . We assume a benevolent government, so that the third faction maximizes total welfare $W$ in the economy, ${ }^{13}$ as given by equation (7). The three factions bargain with each other when deciding about the price and quality of the good offered by firm 1 . As previously, each faction is characterized by a bargaining weight inside the firm.

Formally, we have that

Definition 4 A FUNE with government intervention in firm 1 (FUNE-G1) is a vector $\left(p_{1}, q_{1}, p_{2}, q_{2}\right)$, a triple $\left(a_{1}, b_{1}, a_{2}\right) \in[0,1]^{3}$ with $\left(a_{1}, b_{1}, a_{1}+b_{1}, a_{2}\right) \in[0,1]^{4}$ such that (i) given $\left(p_{1}, q_{1}\right),\left(p_{2}, q_{2}\right)=\arg \max \left(\Pi_{2}-\bar{\Pi}_{2}\right)^{a_{2}}\left(R_{2}-\bar{R}_{2}\right)^{1-a_{2}}$, (ii) given $\left(p_{2}, q_{2}\right),\left(p_{1}, q_{1}\right)=\arg \max \left(\Pi_{1}-\bar{\Pi}_{1}\right)^{a_{1}}\left(R_{1}-\bar{R}_{1}\right)^{1-a_{1}-b_{1}}(W-\bar{W})^{b_{1}}$ where $W$ is given by equation (7).

The impasse utilities of the factions in firm $i$ are given by the value of their objective function in case there is no agreement inside firm $i$, in which case we suppose that the firm is not active on the market. For profit-maximizing and revenue-maximizing firms, the impasse utilities are zero: $\bar{\Pi}_{i}=0, \bar{R}_{i}=0, i \in\{1,2\}$. For the welfare-maximizing faction in firm 1 , the impasse utility is the welfare level when only firm 2 produces. In that case, everyone buys good 2 and the aggregate welfare level is given by

$$
\bar{W}=q_{2} \bar{\lambda}(1+\gamma)-c\left(q_{2}\right)
$$

Observe that the impasse utility of welfare-maximizers is a function of the quality produced by firm 2, but not of its price (since we assume that everyone's valuation of the good is high enough that everyone buys from firm 2).

Our objective is to study the impact on the industry equilibrium of the government taking a participation in the high quality firm. To do so, we need to relate the extent

affect our normative analysis as long as we maximize unweighted surplus. Introducing an exogenous cost of public funds would of course make such expenditures less appealing.

${ }^{13}$ For instance, the directors that represent the government in the Board are told to maximize this objective. 
of the public participation in firm 1 to the bargaining weight of the welfare maximizing faction, $b_{1}$. We assume a monotone increasing relationship, so that we can concentrate on the bargaining weight of this faction.

Our benchmark situation is the eFUNE without government intervention obtained in the previous section and denoted by eFUNE $E_{0}$. To concentrate on the impact of government intervention, we keep the relative bargaining weight of the profit- and revenuemaximizing factions constant in both firms as we increase the bargaining weight of the welfare-maximizers in firm 1 . That is, we keep both $\left(1-a_{2}\right) / a_{2}$ and $\left(1-a_{1}-b_{1}\right) / a_{1}$ constant at the level reached in this unique eFUNE (resp. 1.25 and 12.85) and study the FUNE-G1 associated with each value of $b_{1}$. To each value of $b_{1}$ is associated (at most) one FUNE-G1. Finally, we assume that the intensity of the externality is such that $\gamma=1$ in equation (1).

It is easy to see that the presence of a welfare-maximizing faction increases aggregate welfare in the following limited sense. The first order condition for firm 1 in a FUNE-G1 equilibrium can be expressed as

$$
\frac{a_{1}}{\Pi_{1}} \nabla_{1} \Pi_{1}+\frac{1-a_{1}-b_{1}}{R_{1}} \nabla_{1} R_{1}=\frac{-b_{1}}{W-\bar{W}} \nabla_{1} W
$$

where

$$
\nabla_{1} W=\left(\frac{\partial W}{\partial p_{1}}, \frac{\partial W}{\partial q_{1}}\right)
$$

while $\nabla_{1} \Pi_{1}$ and $\nabla_{1} R_{1}$ are given by (4). So, contrary to the 2 faction case studied in section 3 , there exists a direction in the price-quality space that would simultaneously increase profits and revenue in firm 1 (since the LHS of (14) is typically not equal to zero) but the welfare-maximizing faction prevents the other two factions from moving into this direction. In other words, removing the welfare-maximizing faction (or simply decreasing its bargaining weight) at any FUNE-G1 with $b_{1}>0$ would result in the other two factions in firm 1 moving in a direction that would decrease aggregate welfare.

This argument is purely local and limited, because it falls short of taking into account the reaction of the other firm to the deviation by firm 1 as $b_{1}$ decreases. In order to assess the full impact of modifying $b_{1}$, we have to compute the FUNE-G1 associated to 
each value of $b_{1},{ }^{14}$ and compare the welfare level attained in each equilibrium. As $b_{1}$ increases ${ }^{15}$, we have that

- the quality offered by both firms increases monotonically and moves closer to the optimal qualities: $q_{1}$ increases from 48.4 to 128.8 as $b_{1}$ increases (the optimal value of $q_{1}$ is 220 ) while $q_{2}$ increases from 40.5 to 86.7 (while the optimal value of $q_{2}$ is 103.6);

- the proportion of people buying the low quality good increases with $b_{1}$ (from $37.5 \%$ to $64.5 \%$ ) and moves closer to the optimal proportion, $85.8 \%$;

- the efficiency of the FUNE-G1 increases monotonically, from $56 \%$ to $94 \%$ (see Figure 2).

[Insert Figure 2 around here]

We summarize all this in the next Result:

Result 3 As the bargaining weight of the welfare maximizing faction in the high quality firm increases, the efficiency of the corresponding FUNE-G1 allocation increases monotonically, with the qualities of both goods increasing and moving closer to their optimal levels, while the proportion of people buying the low quality good increases and also moves closer to its optimal level.

We thus obtain not only that the government taking a participation (by which we mean introducing a third faction bent on maximizing welfare) in the high quality firm helps increasing the efficiency of the equilibrium allocation, but also that efficiency is monotonically increasing in the bargaining weight of the welfare maximizers. All these regularities also hold true for the other two eFUNES (denoted by eFUNE $\mathrm{var}_{1}$ and

\footnotetext{
${ }^{14}$ Finding FUNE-G1s requires solving 4 equations (first order conditions with respect to price and quality for statements (i) -for firm 2 - and (ii) -for firm 1-in Definition 4$)$ in 5 unknowns $\left(p_{1}, q_{1}, p_{2}, q_{2}\right.$ and $\left.b_{1}\right)$, given that we keep $a_{2}$ and $\left(1-a_{1}-b_{1}\right) / a_{1}$ constant at the level reached in the unique eFUNE. We choose a value for $b_{1}$ and solve for the other 4 unknowns. We also check that the second order conditions are satisfied.

${ }^{15}$ We limit $b_{1}$ to $[0,3 / 4]$ because of convergence problems for $b_{1}>0.75$.
} 
$\left.\mathrm{eFUNE}_{\mathrm{var} 2}\right)$ that we have identified in section 4 by modifying the shape of either the function $\alpha(\mu)$ or $Q(r)$. They also hold true if the government invests in the low quality firm rather than in the high quality firm.

\section{The impact of the externality intensity}

In this section, we test the robustness of the results obtained in the previous section to variations in the externality intensity (the value of parameter $\gamma$ in equation (1)). Recall that the value of $\gamma$ does not impact the set of FUNEs without government intervention, nor the eFUNE we selected. We thus start from the same eFUNE as in the previous section. On the other hand, $\gamma$ impacts the efficiency reached in this eFUNE, and also the FUNE-G1 corresponding to any value of $b_{1}$ (because $\gamma$ appears in the first order condition (14) with a welfare-maximizing faction).

We have proceeded in the same way as in the previous section, starting from the eFUNE obtained in section 4 and maintaining constant the relative bargaining weights of the profit and revenue-maximizing factions in both firms while we increase $b_{1}$. Figure 3 reports by how much total surplus increases (compared to the original eFUNE without welfare maximizers) as a function of the bargaining weight of welfare maximizers $\left(b_{1}\right)$ for several values of the externality intensity $\gamma$. We obtain the following results:

- Whatever the value of $b_{1}>0$, the gain in surplus is always positive and is larger when the externality intensity $\gamma$ is bigger. Moreover, the marginal gain in surplus $\left(\partial W / \partial b_{1}\right)$ weakly increases with the value of $\gamma$, for any value of $b_{1}$.

- The surplus gain increases monotonically with $b_{1}$ and converges to a horizontal asymptote. The value of $b_{1}$ above which welfare becomes quasi- horizontal in Figure 3 is increasing in $\gamma$. In other words, pushing the bargaining weight of the welfare maximizers above a certain threshold brings nearly no additional increase in aggregate welfare.

- Whatever the value of $\gamma \in[0,1]$, the quality of both goods and the market share of the low quality good increase with $b_{1}$. The high quality level and the fraction of 
people consuming the low quality good are always lower than their optimal level. As for the low quality level, it is lower than its optimal level, except when $\gamma$ is low $(\gamma \leq 1 / 2)$ and $b_{1}$ large - i.e., in the case where $\gamma$ is low, the lowest quality level is driven above its optimal value as the welfare-maximizers bargaining power increases.

[Insert Figure 3 around here]

We summarize in the following Result:

Result 4 Government's participation in the high quality firm is more desirable (i.e., increases more total surplus) when the externality intensity is larger. The marginal gain in welfare (when the bargaining weight of the governmental faction increases) rises with the externality intensity (for given $b_{1}$ ) but decreases with the bargaining weight of the welfare maximizing faction (for given $\gamma$ ), and converges to zero. Raising $b_{1}$ increases both quality levels and the proportion of people buying the low quality good. The low quality level overshoots its optimal level when the externality intensity is low enough $(\gamma \leq 1 / 2)$ and when the bargaining power of the welfare maximizers is large enough.

It is not surprising that government's intervention is more desirable (both in absolute terms and at the margin) when the externality intensity is large, since the FUNEs without government intervention perform particularly badly (large under-provision of quality by both firms) in this case. It is also quite intuitive that the marginal increase in welfare (when $b_{1}$ is increased) is lower when the government faction is already powerful inside the firm. Interestingly, a powerful welfare-maximizing faction in firm 1 may induce an over-supply of quality in the low quality firm (when the externality intensity is low enough).

We now put these welfare gains in perspective by looking at how the efficiency of any FUNE-G1 equilibrium (measured as previously as the ratio of the equilibrium welfare to the maximum, Pareto efficient, welfare), evolves with the welfare maximizers' bargaining weight $b_{1}$ for several values of $\gamma$ (see Figure 4 ). 
[Insert Figure 4 around here]

We obtain the following results:

- When the bargaining weight of the welfare maximizers $b_{1}$ is close to zero, efficiency is decreasing with the externality intensity $\gamma$ : the more people care for the average good quality, the less efficient the "laissez faire" FUNE allocation.

- The ranking is reversed for sufficiently high values of $b_{1}$ : the efficiency of FUNE-G1 with powerful welfare-maximizers increases when people care more for the average good quality.

- Whatever the value of the externality intensity, the government taking a participation in the high quality firm never allows to reach the Pareto efficient allocation. The gain in surplus from this participation, measured as a proportion of the maximum attainable surplus rather than in absolute terms as in Figure 3, increases with the externality intensity.

We summarize in the following Result:

Result 5 The gain in efficiency (measured as the ratio of equilibrium to maximum attainable welfare) when the government takes a participation in the high quality firm increases with the externality intensity. If the bargaining weight of the welfare maximizers is low, the efficiency of FUNEs decreases with the externality intensity, while it increases if $b_{1}$ is large enough. Neither partial nor total nationalization of the high quality firm allows to attain the Pareto efficient surplus level.

The regularities summarized in Results 4 and 5 also hold true when one takes as a starting point either the allocation eFUNE $\mathrm{var}_{1}$ or $\mathrm{eFUNE}_{\mathrm{var} 2}$ rather than $\mathrm{eFUNE}_{0}$, and when the government invests in firm 2 rather than in firm 1.

\section{Conclusion}

In this paper, we have looked at competition between two firms providing differentiated goods when individuals may care for the average quality of the goods supplied and 
when firms are composed of various factions whose objectives differ. As such, this analysis belongs to the mixed oligopoly literature, which studies competition between firms whose objectives differ. Our main assumptions are that firms are composed of both profit and revenue maximizers, and that these two factions bargain with each other when choosing price and quality of the good their firm is offering. An equilibrium allocation, called Firm Unanimity Nash Equilibrium (FUNE), corresponds to a Nash equilibrium between firms when factions inside each firm bargain efficiently.

Using numerical simulations, we first show that there is a two-dimensional manifold of FUNEs, each characterized by the relative bargaining weight of the revenue maximizers in each firm. The normative properties of FUNEs are bad, with qualities provided being too low and too many consumers buying the high quality good. We then open the bargaining power "black box" and provide an explanation as to how their values are determined. Providing such an explanation has an obvious interest by itself, and also allows us to narrow down the set of equilibria and indeed to obtain unicity. Our next step is then to introduce public intervention in the form of the government taking a participation in one firm. We assume that participation introduces a third faction in this firm, whose objective is to maximize total surplus. We obtain that efficiency is monotonically increasing with the bargaining weight of the welfare maximizing faction, although the marginal gain in welfare tends to zero as the bargaining weight becomes large enough. A larger value of the externality intensity also makes government's intervention more desirable, since it increases both the marginal and absolute gain in welfare from this intervention. We obtain the same qualitative results whether the government invests in the high-quality or the low-quality firm.

The approach used in this paper could be extended in several directions. First, we concentrate on one form of government intervention, namely the introduction of welfaremaximizers in one firm's board of directors. It would be interesting to contrast this with other, more light handed, forms of regulations such as price caps for instance. Second, we have assumed that the government faction maximizes welfare. It might be interesting to allow for other objectives for the faction appointed by the government, even with 
a benevolent government. ${ }^{16}$ Third, we have abstracted from many shortcomings of the government taking a participation in one firm, like incentive issues or financial expenditures associated with this policy when the cost of public fund is large. We have done this in order to focus on whether there is a case to be made for such a public intervention in the most favorable setting. Introducing incentive issues would obviously restrict the set of parameters for which taking a participation in a firm is desirable.

\section{References}

[1] Baumol W, 1958, On the Theory of Oligopoly, Economica 25,187-98.

[2] Cantos-Sanchez P and R Moner-Colonques, 2006, Mixed Oligopoly, Product Differentiation and Competition for Public Transport Services, The Manchester School, 74 (3), 294-313.

[3] Crampes C and A Hollander, 1995, Duopoly and Quality Standards, European Economic Review, 39, 71-82.

[4] Fershtman C and K Judd, 1987, Equilibrium incentives in oligopoly, American Economic Review, 77, 927-40.

[5] Grilo I, 1994, Mixed duopoly under vertical differentiation, Annales d'économie et de statistique, 33, 91-112.

[6] Jiang L, 2006, Welfare Analysis of Privatization in a Mixed Market with Bargaining, Contemporary Economic Policy, 24 (3), 395-406.

[7] Matsumara T, 1998, Partial privatization in mixed duopoly, Journal of Public Economics 70, 473-483.

[8] Parris H, P Pestieau, P Saynor, 1987, Public Enterprise in Western Europe, Croom Helm, London.

[9] Pita-Barros P and X Martinez-Giralt, 2002, Public and Private Provision of Health Care, Journal of Economics \& Management Strategy, 11 (1), 109-133.

\footnotetext{
${ }^{16}$ See White (2002) for instance.
} 
[10] Roemer J, 1999, The democratic political economy of progressive income taxation, Econometrica 67, 1-19.

[11] Roemer J, 2001, Political Competition. Theory and Applications, Harvard University Press, Cambridge, USA.

[12] Roemer, Lee W and K Van der Straeten, 2005, Racism, Xenophobia and Redistribution: A study of multi-issues politics in advanced democracies, New York and Cambridge: Russel Sage Foundation and Harvard University Press.

[13] Romero L and E Del Rey, 2004, Competition between Public and Private Universities: Quality, Prices and Exams, Working Paper 046423, University Carols III, Madrid.

[14] Seabright P, 2004, The Company of Strangers: A Natural History of Economic Life, Princeton University Press.

[15] White M, 2002, Political manipulation of a public firm's objective function, Journal of Economic Behavior \& Organization 49, 487-499.

[16] Willner J, 1999, Policy objectives and performance in a mixed market with bargaining, International Journal of Industrial Organization 17, 137-145. 


\section{Appendix}

Proof. of Proposition 1

Equate the right hand sides of the first order conditions for firm 1 (equations (5) and (6)):

$$
\frac{1-F\left(\lambda^{*}\right)-\left[p_{1}-c\left(q_{1}\right)\right] f\left(\lambda^{*}\right) \frac{\partial \lambda^{*}}{\partial p_{1}}}{F\left(\lambda^{*}\right)-1+p_{1} f\left(\lambda^{*}\right) \frac{\partial \lambda^{*}}{\partial p_{1}}}=\frac{-c^{\prime}\left(q_{1}\right)\left(1-F\left(\lambda^{*}\right)\right)-\left[p_{1}-c\left(q_{1}\right)\right] f\left(\lambda^{*}\right) \frac{\partial \lambda^{*}}{\partial q_{1}}}{p_{1} f\left(\lambda^{*}\right) \frac{\partial \lambda^{*}}{\partial q_{1}}}
$$

Manipulating this equation reduces it to

$$
\frac{c\left(q_{1}\right)}{q_{1}-q_{2}} \lambda^{*}=c^{\prime}\left(q_{1}\right)\left(\frac{p_{1}}{q_{1}-q_{2}}-\frac{1-F\left(\lambda^{*}\right)}{f\left(\lambda^{*}\right)}\right) .
$$

Proceeding in like manner for firm 2, we obtain

$$
\frac{-c\left(q_{2}\right)}{q_{1}-q_{2}} \lambda^{*}=c^{\prime}\left(q_{2}\right)\left(\frac{F\left(\lambda^{*}\right)}{f\left(\lambda^{*}\right)}-\frac{p_{2}}{q_{1}-q_{2}}\right) .
$$

Using the fact that

$$
\frac{c(q)}{c^{\prime}(q)}=\frac{q}{r},
$$

and dividing equation (15) by $c^{\prime}\left(q_{1}\right)$ and equation (16) by $c^{\prime}\left(q_{2}\right)$, and then adding the equations gives

$$
\frac{\lambda^{*}}{r}=\lambda^{*}+\frac{2 F\left(\lambda^{*}\right)-1}{f\left(\lambda^{*}\right)} .
$$


Figure 1: FUNEs in the (Price, Quality) space

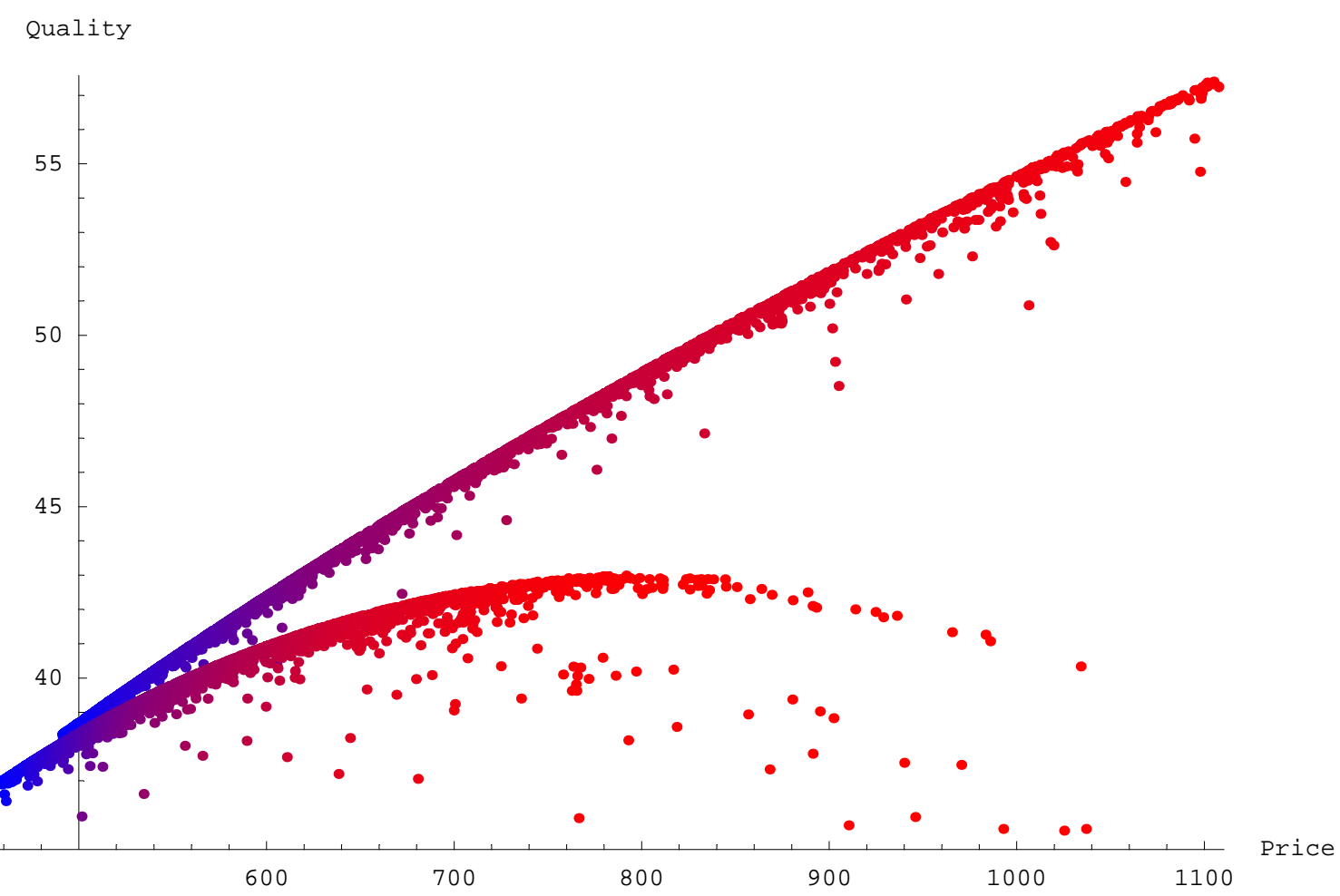


Figure 2 : Efficiency of FUNE - G1 as a function of b1 when $\gamma=1$

Efficiency

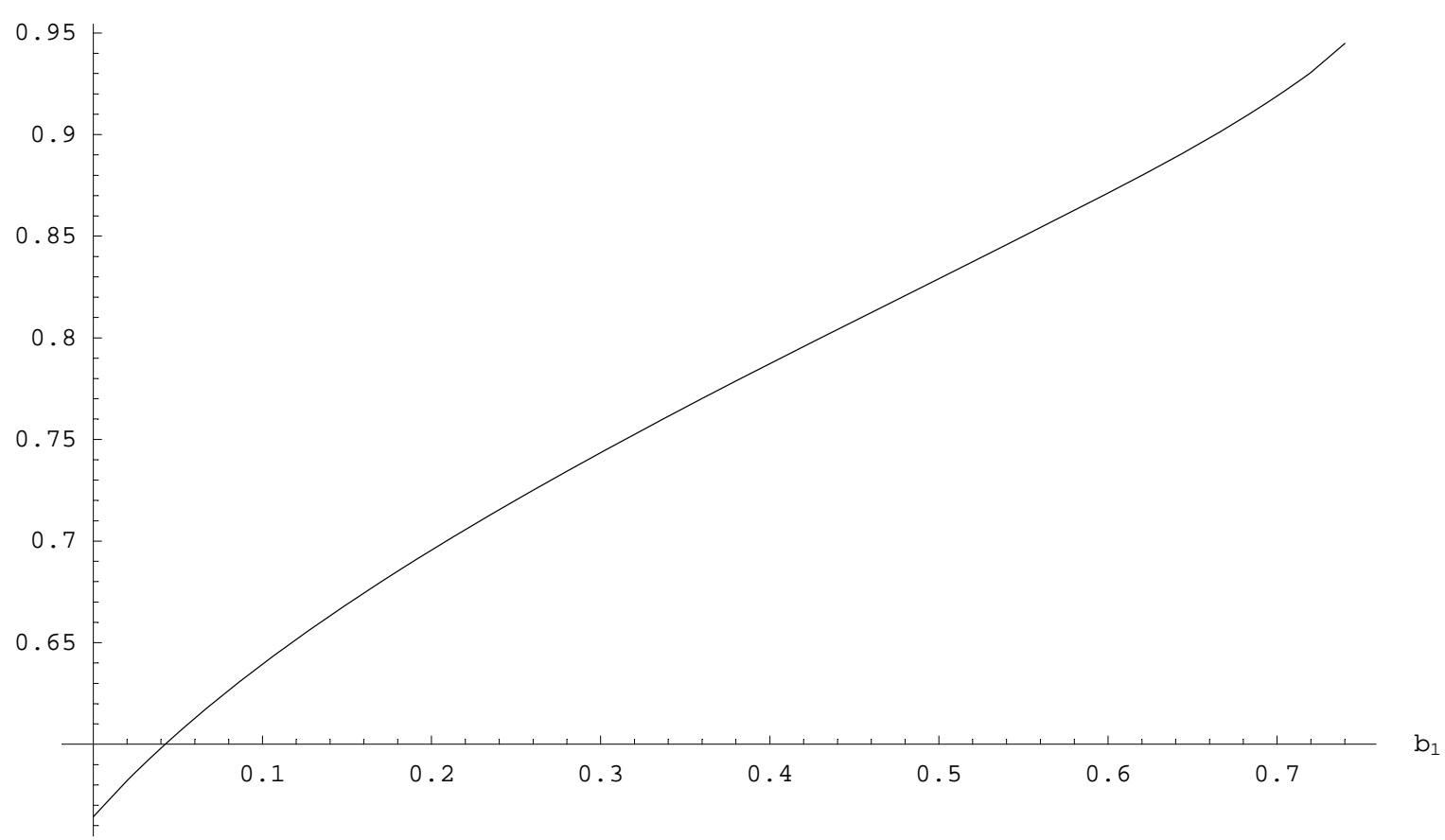


Figure 3 : Increases in surplus as a function of b1 for several values of $\gamma$

Surplus increase from $b_{1}=0$
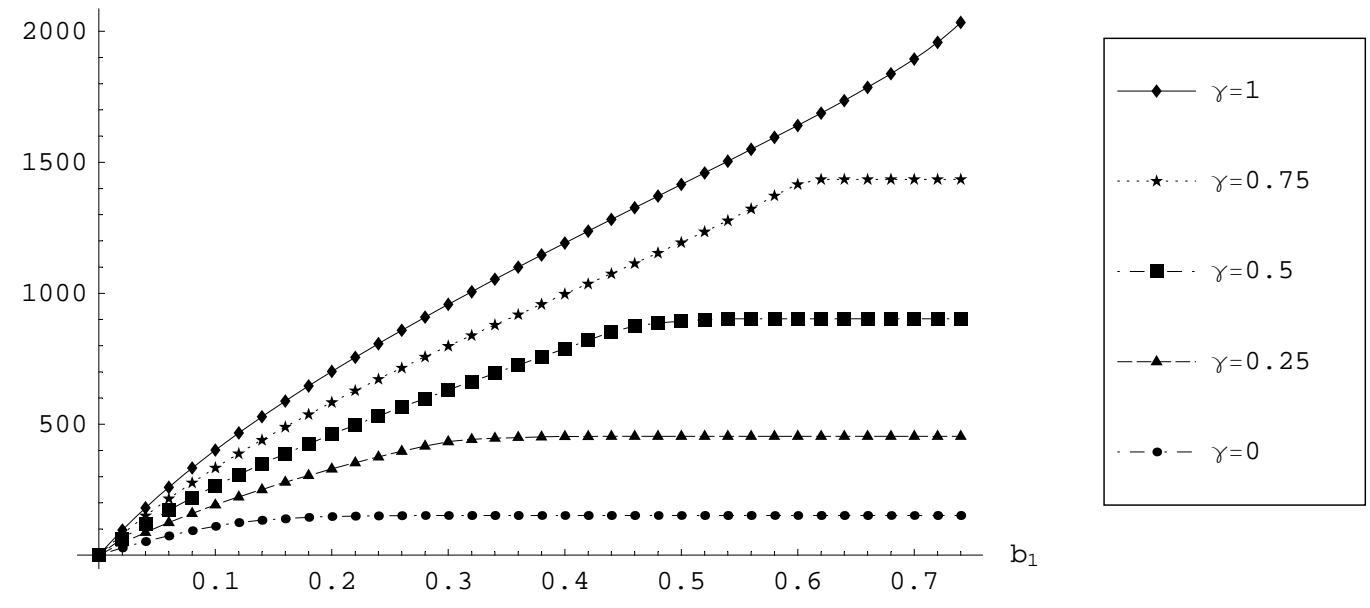
Figure 4: Efficiency as a function of $b 1$ for several values of $\gamma$

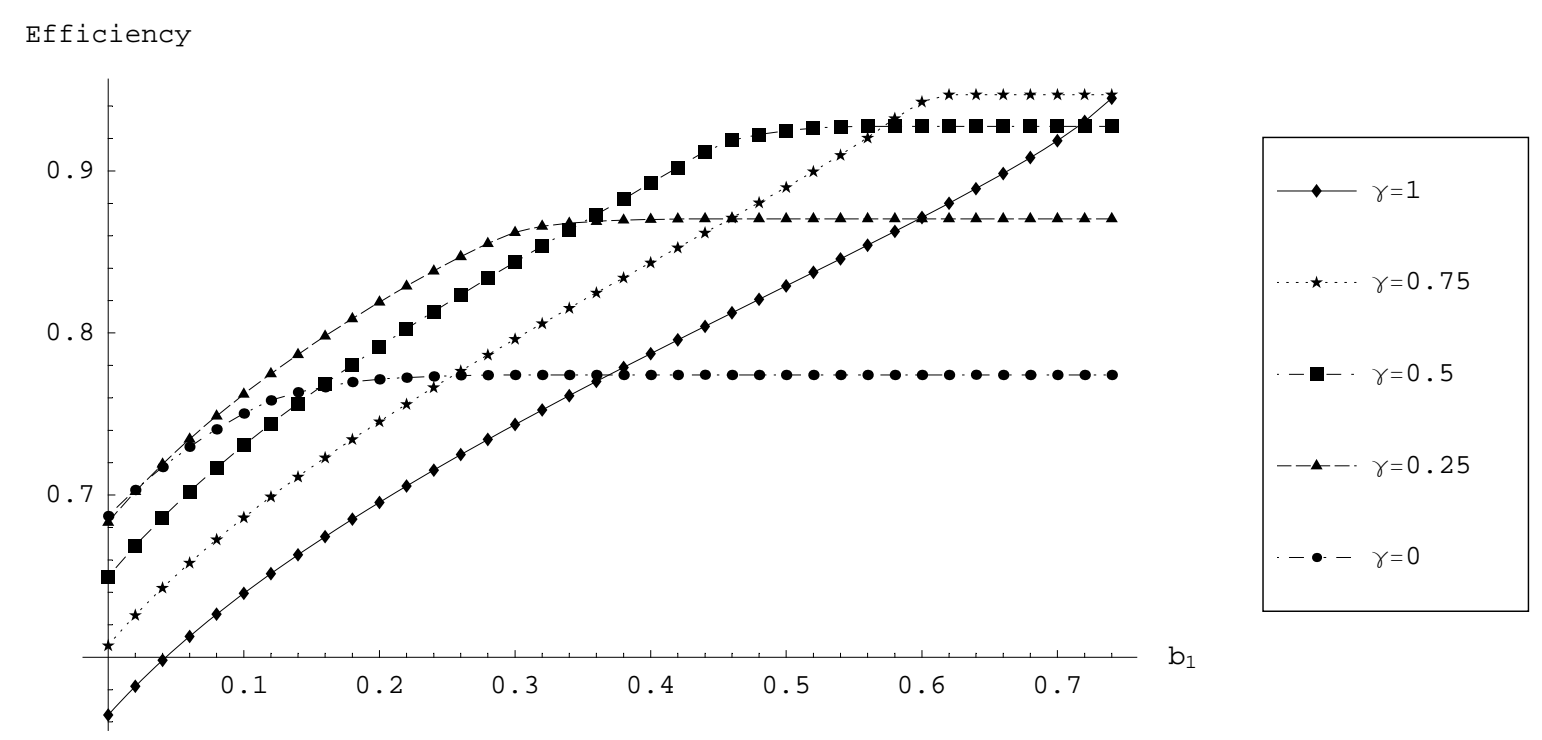

